Revista Española de Derecho Internacional
Sección BIBLIOGRAFÍA
Vol. 68/1, enero-junio 2016, Madrid, pp. 255-269
http://dx.doi.org/10.17103/redi.68.1.2016.5
C 2016 Asociación de Profesores
de Derecho Internacional
y Relaciones Internacionales

Sección coordinada por C. EsPósito (Derecho internacional público), E. ZaBALO (Derecho internacional privado) e I. RODRÍGUEZ (Relaciones Internacionales)

\title{
A) RECENSIONES
}

IbÁÑEz MuÑoz, J. y SÁNChez AviLÉs, C. (dirs.), Mercados ilegales y violencia armada. Los vínculos entre la criminalidad organizada y la conflictividad internacional, Madrid, Tecnos, 2015, 255 pp.

La obra colectiva que es objeto de comentario en estas páginas, dirigida por el Profesor Josep Ibáñez y la Investigadora Constanza Sánchez, reúne las aportaciones de una decena de especialistas en el ámbito de las Relaciones Internacionales que se interrogan sobre las interacciones que se han establecido entre el auge contemporáneo de diversas formas de criminalidad transnacional organizada y la alteración de los modelos clásicos de la conflictividad armada. Ciertamente, ha sido señalada ya en múltiples ocasiones la relación que existe entre ambos fenómenos. Pero el valor añadido de la presente investigación radica en el elevado calado analítico de las respuestas que se dan a esa pregunta. Los autores de este libro no se limitan, en ese sentido, a agavillar un conjunto de estudios de caso sobre la cuestión para que el lector saque conclusiones por sí mismo, sino que realizan un considerable esfuerzo heurístico destinado a sintetizar las formas de interrelación entre ambos fenómenos, comprenderlas y, por último, apuntar las implicaciones que esta confluencia tiene para la seguridad internacional.
En el estudio introductorio, el Profesor J. Ibáñez presenta el marco teórico del análisis al señalar que la interacción entre conflictos armados y criminalidad organizada se puede estudiar en función de la naturaleza y del grado de influencia mutua que se da entre ambos fenómenos encontrándose, en un extremo del continuo, el supuesto de su simple coexistencia sobre un espacio geopolítico dado y, en el opuesto, la situación en la que la presencia de cualquiera de ellos es indisociable de la existencia del otro. Dentro de esta escala de menor a mayor rozamiento, las variables que definen cada escenario son: los actores principales (que pueden ser completamente distintos o interactuar dentro de marcos colaborativos o competitivos); los objetivos y motivaciones que les guían (lucrativos, ideológicos o mixtos); las actividades tácticas, con lógicas diferenciadas o concurrentes, que desarrollan tanto las partes en un conflicto armado como los grupos criminales; y, finalmente, la clase de respuesta política (independiente o conjunta) que proporcionan las autoridades ante el desafío planteado por ambas realidades. 
Las inflexiones que se producen en torno a estas cuatro variables permiten articular una tipología que ordena en cinco categorías la aproximación a las formas de confluencia entre la violencia armada y la criminalidad organizada: $c o-$ existencia, cuando la presencia paralela de ambos fenómenos en un territorio no implica influencia; parasitismo, cuando una realidad aprovecha las condiciones de la otra, desarrollándose a su costa; dependencia, en los casos en los que bien la criminalidad organizada depende de la pervivencia del conflicto para seguir extrayendo beneficios de las operaciones en los mercados ilegales o bien los contendientes en un conflicto recurren a estos mercados para financiar su capacidad militar; interdependencia, cuando se desarrolla una dinámica perversa de dependencia simétrica entre ambas realidades; y simbiosis, que se produce en las situaciones de fusión en el tiempo de ambos fenómenos, en un contexto de debilidad estatal, de modo que las organizaciones criminales acaban siendo contendientes en el conflicto armado y viceversa.

A partir de ese marco analítico, los autores desmenuzan varios estudios de caso en los que se observa la interacción entre las dos realidades. En el Capítulo I, Constanza Sánchez presenta una panorámica global de los mercados de drogas ilegales, en particular de los de opiáceos y cocaína, enfatizando su carácter global. En el Capítulo II, David Bewley-Taylor analiza los vínculos entre el mercado ilegal de opio y la violencia armada en Afganistán. Las conflictivas situaciones de México y Colombia y su interacción con el tráfico de cocaína son abordadas en los Capítulos III y IV, a cargo, respectivamente, de Octavio Rodríguez (que finaliza su exposición respondiendo - de manera negativa - a la pregunta de si la situación de violencia mexicana debiera ser calificada como conflicto armado) y de Erika M. Rodríguez, que problematiza la tesis que considera al narcotráfico como el principal factor explicativo del conflicto colombiano, a fin de aportar una visión más compleja de esa interacción y señalar, incluso, que «es posible ir un paso más allá, dar otra vuelta al argumento y convertir al narcotráfico no en la causa sino en otra de las consecuencias de las deficiencias estructurales que condujeron a la confrontación armada» (p. 118).

Las referencias empíricas al continente africano, por otra parte, se abren con un Capítulo V en el que Pablo Pareja analiza los patrones de relación entre la delincuencia pirática y la conflictividad armada en Somalia, advirtiendo sobre la práctica inexistencia de lazos entre los actores de ambas realidades. En el Capítulo VI, Marta Abegón examina los vínculos existentes entre el comercio ilícito de diamantes y los conflictos armados que se han desarrollado en países como Sierra Leona, Liberia, Angola, República Democrática del Congo o Zimbabue, poniendo énfasis sobre las estrategias de cooperación internacional que han sido diseñadas para limitar el tráfico de diamantes de sangre. Y, por último, en el Capítulo VII, Jordi Quero se sirve de un enfoque regional para aproximarse a la relación recursiva que se entabla en el Sahel entre el conflicto armado existente y diversas modalidades de criminalidad organizada, entre las que se cuentan los tráficos ilegales de armas, drogas o migrantes y los secuestros de extranjeros.

Respecto a Europa, Ignasi Torrent trata en el Capítulo VIII el caso balcánico, destacando el rol desempeñado por los grupos criminales en el espacio posbélico de países como Croacia y Serbia (en los que se produce una considerable inserción de las redes delictivas en las propias estructuras estatales), Bosnia y Kosovo (donde la criminalidad organizada presenta una génesis más ligada a grupos bélicos paramilitares) o Albania y Montenegro, en los que prima la existencia de un tejido criminal transnacional que está articulado sobre una base clánica o familiar. Por último, el libro se 
cierra con un interesante trabajo de Caterina García sobre el papel de la Oficina de las Naciones Unidas contra la Droga y el Delito (UNDOC) que para la autora «es reconocida como la autoridad de referencia en el ámbito multilateral de la lucha contra la criminalidad transnacional organizada» (p. 219); resulta elocuente que se haya seleccionado para el estudio de caso la UNDOC — frente a la opción operativa que hubiese brindado, por ejemplo, INTERPOL- puesto que parece reflejar la voluntad de la autora, y diría que también del resto de los participantes en la obra, de llevar a cabo un análisis de discurso sobre el relato construido, en este caso por las instituciones multilaterales, en torno al crimen transnacional a fin de cuestionar cómo se le define, cómo se decide entrelazarlo (o no) con otras formas de violencia y, a la postre, cómo se combate.

A partir de los análisis empíricos se concluye - aunque esta sea una síntesis de trazo muy grueso- que la coexisten- cia entre los fenómenos objeto de estudio predomina en Somalia, que las relaciones parasitarias se observan en algunas regiones de Colombia y en países como Ghana, Mali y Liberia, que la dependencia se aprecia en el Sahel, Sierra Leona, Costa de Marfil, Angola y en los Balcanes, que la interdependencia resulta paradigmática en Afganistán y que los elementos propios de la relación simbiótica se muestran, sobre todo, en algunos momentos históricos del caso colombiano.

Como señalaba al principio, esta es una obra de notable aliento teórico, bien escrita, homogénea en sus partes pese a ser polifónica y de recomendable lectura. Ha sido fruto de una ayuda para la investigación del Institut Català Internacional per la Pau donde, imagino, se habrá evaluado satisfactoriamente el resultado obtenido.

Carlos TeIJo García

Universidad de Santiago de Compostela http://dx.doi.org/10.17103/redi.68.1.2016.5.01

Méndez SiLVA, R., El Consejo de Seguridad de las Naciones Unidas y los casos de Afganistán e Irak, México, Universidad Nacional Autónoma de México, $276 \mathrm{pp}$.

La obra que presenta el Profesor Doctor Ricardo Méndez Silva, prestigioso Profesor de Derecho internacional en la Facultad de Ciencias Políticas y Sociales e investigador del Instituto de Investigaciones Jurídicas de la Universidad Nacional de México, constituye una aportación práctica importante en lo que atañe a la materia global elegida: el tratamiento del uso legítimo de la fuerza en el sistema de la Carta de las $\mathrm{Na}$ ciones Unidas. Este objeto tan complejo en su análisis teórico y en su aplicación práctica, ofrece al autor la posibilidad de revisarlo desde diversas perspectivas: una perspectiva histórica, ofreciendo al lector un repaso cronológico, bastante exhaustivo, sobre la aplicación del mismo desde los inicios del funcionamiento de la ONU hasta la actualidad; una perspectiva doctrinal, analizando todas las corrientes interpretativas del mencionado concepto, desde su determinación conceptual hasta su relación con figuras conexas y derivadas del mismo y, por último, una conclusión final, inducida de la praxis efectiva de este mecanismo de hacer cumplir el entramado estructural del Derecho internacional como sistema normativo en sí mismo.

El estudio que se nos presenta ofrece al lector una asimilación asequible de conceptos y de análisis, en un contexto de intereses estatales tan políticos como estratégicos, derivado, con toda lógica, de una sociedad compuesta de relaciones interestatales. 
De esta suerte, la Primera parte de la monografía (Capítulo I) analiza la historia de la progresiva limitación y ulterior prohibición del uso de la fuerza en las relaciones entre Estados, haciendo referencia expresa a su primaria previsión por los Pactos previos y de la Sociedad de Naciones y, posteriormente, de manera más expresa, al marco jurídico recogido ya en la Carta de la Organización de las Naciones Unidas, como sabemos, previsto en los Capítulos VI y VII de la misma, así como su conexión con el resto de Principios Estructurales. Es relevante señalar cómo en la presente monografía también se hace referencia a las sanciones internacionales, como respuesta a un incumplimiento de la prohibición, así como a los efectos negativos que las mismas han ocasionado al ser aplicadas a determinados Estados incumplidores. Analiza, cronológicamente, como ejemplos de intervención del Consejo de Seguridad (con sus respectivos problemas) los asuntos de Corea (1950), Malvinas (1981) e Irak-Kuwait (1981), deteniéndose en la Resolución del Consejo de Seguridad 678 de 1990, al considerarla como la primera aplicación verdadera del Capítulo VII desde la creación de la Carta de la ONU, en concreto, como una situación de legítima defensa colectiva, tras una situación de guerra fría que, teóricamente, concluyó con la desaparición de la antigua URSS.

Los atentados del 11-S de 2001 constituyen un episodio importante dentro de este análisis. Son catalogados por el autor como el fundamento que utilizaron ciertos Estados y parte de la doctrina para justificar una situación de «legítima defensa colectiva». Al tratarse de un enfrentamiento armado internacional, no convencional, ya que una de las partes no está identificada (pues se trata de un grupo terrorista y no de un Estado), el hecho de protegerse de posibles y futuras agresiones legitimaría un ataque previo sobre los territorios de los Estados sospechosos de encubrir, financiar y soste- ner a este tipo de actores internacionales transfronterizos. De ahí que los Estados que han justificado este tipo de autodefensa, la encubran bajo las previsiones de la Resolución 678, junto a otras, del Consejo de Seguridad de las Naciones Unidas.

En la segunda parte de este Capítulo I el Profesor Méndez aborda un estudio sobre las funciones del Consejo de Seguridad de las Naciones Unidas en materia de paz y seguridad mundiales. Este estudio le va a facilitar llegar a abordar una nueva cuestión, conexa, eso sí, a la anterior, como es la imperante necesidad de reformar de la Carta de las Naciones Unidas, en especial, del Consejo de Seguridad, clave en el control legítimo del uso de la fuerza en el propio marco de la Carta. El autor se replantea el número de Estados miembros de este Órgano y su identidad. Considera que tanto Japón como la República alemana, como segundo y tercer mayores contribuyentes de los gastos de la ONU, deberían constituirse como miembros permanentes del Consejo de Seguridad. Por otra parte, en la Cumbre de las Naciones Unidas de 2005, ya se puso de manifiesto el problema del derecho de veto de los Estados permanentes del Consejo de Seguridad, y lo que había supuesto su ejercicio, por lo que se llegó a ofrecer dos alternativas de solución (las denominadas A y B), que en realidad, sin alterar la composición de los miembros permanentes del Consejo, sí que modificaba los supuestos de utilización legítima del veto. A estas dos alternativas se añadió una tercera formulada por el denominado Grupo de los 4 (Estados que como Alemania, Brasil, India y Japón se autoseleccionaban como legitimados por representar diferentes Continentes con ninguna representación en el órgano sometido al estudio de revisión - salvo Alemania- para formar parte del Consejo de Seguridad con el apoyo de otros Estados). Otras propuestas fueron protagonizadas por el Grupo «Unidos por el Consenso», por la Unión Africana o por 
Estados Unidos de América. La Cumbre no dio lugar a ninguna propuesta seria de modificación de la Carta. Concluyó que la modificación orgánica del Consejo de Seguridad no tenía prioridad por el momento. Posteriormente, la realidad fáctica nos demostraría otra cosa muy diferente.

El Profesor Ricardo Méndez en esta misma primera parte de su trabajo se introduce en un nuevo sector del Derecho internacional, el de los Derechos Humanos, y lo hace cuando al estudiar "Las funciones ampliadas del Consejo de Seguridad" se adentra en las operaciones de mantenimiento de la paz. Tras realizar un análisis de las mismas desde lo que el autor denomina «un universo de expansión", diferencia entre las misiones clásicas (18 en total) desde 1948 a 1989 y las misiones actuales (en número de 49) desde 1989 a 2012. Estas últimas constituyendo una amalgama de actividades destinadas a más de una finalidad, aparte del restablecimiento de la paz y su consolidación (creación de la Comisión de Consolidación de la Paz, en diciembre de 2005, compuesta por 31 Estados), adentrándose asimismo en la intervención de carácter o con carácter humanitario sin dejar de invocar y respetar el principio estructural de no injerencia interna en los Estados y, por tanto, el necesario consentimiento de los mismos para este tipo de operaciones internacionales, de iniciativa onusiana.

Para terminar esta primera parte, como ya expusimos, destinada a elaborar un discurso institucional sobre el Consejo de Seguridad de las Naciones Unidas y dentro de lo que denomina las funciones ampliadas del mismo, examina el papel del Consejo como creador de Tribunales internacionales destinados al conocimiento y atribución de la responsabilidad internacional derivada de graves situaciones de crisis que han puesto en peligro la paz y seguridad mundiales. Sin obviar la cuestión del terrorismo y el problema que ha supuesto para la Comunidad internacional alcanzar una definición consen- suada del mismo, así como la búsqueda de mecanismos de control y prevención para atajar su existencia. Por supuesto que la piratería también queda configurada como una práctica ilícita que atenta contra la paz y seguridad mundiales y el autor la incluye como justificación para la creación de estos órganos jurisdiccionales. Desde esta última perspectiva el Consejo de Seguridad, como órgano de la ONU, se ha investido de poder normativo suficiente como para crear Resoluciones que definen actos ilícitos muy graves y Tribunales Internacionales, capaces de enjuiciar a Estados y a individuos por actos de terrorismo, genocidas y contra la humanidad en su conjunto.

En el Capítulo II, segunda y última parte de esta monografía, el Profesor Méndez Silva ilustra su estudio comentando los casos de Afganistán e Irak. Lo redacta en clave de política-jurídica ofreciéndonos, por un lado, una visión estadista de los hechos acaecidos y las distintas reacciones de determinados personajes muy influyentes en el ámbito internacional que adoptan posiciones y decisiones sin consenso internacional. Asimismo, y por otra parte, analiza las paulatinas Resoluciones del Consejo de Seguridad en la adopción de sanciones internacionales, devastadoras para la población de los Estados afectados. Este análisis, hasta cierto punto ingenuo desde la perspectiva de la subjetividad internacional, nos ofrece una propuesta llamando la atención sobre la cada vez más necesitada, humanización del orden jurídico internacional y, por ello, la necesidad de modificar una institución que, tal como se encuentra configurada en la actualidad, difícilmente funciona por consenso y que cuando lo hace, olvida la existencia de los seres humanos afectados por las duras medidas de ataque y de sanción dirigidas a ese sujeto internacionalmente pleno y soberano como es «el Estado».

M. ángeles Ruiz Colomé

Universidad Complutense de Madrid http://dx.doi.org/10.17103/redi.68.1.2016.5.02 


\section{Orihuela Calatayud, E., Las víctimas y la Corte Penal Internacional. Análisis de la participación de las víctimas ante la Corte, Cizur Menor, Aranzadi, 2014, 275 pp.}

La irrupción de la Corte Penal Internacional (CPI) supuso y está suponiendo un importante revulsivo en las estructuras del Derecho internacional tanto desde la perspectiva de la «inter-estatalidad» como eje vertebrador de la actuación normativa y judicial internacional (véase por ejemplo, la problemática suscitada respecto a las inmunidades soberanas y las obligaciones de cooperación con ocasión de la orden de arresto del Presidente al Bashir de Sudán, cuyo último incidente, a favor de la no detención contraviniendo incluso decisiones judiciales internas, se produjo en junio de 2015 en Sudáfrica, por cierto Estado fundador y parte de la $\mathrm{CPI}$ ), como desde la correlativa vertiente comunitaria que sitúa al individuo y sus derechos como elementos estructurales del reiterado (aunque en curso) proceso de humanización del Derecho internacional. El Estatuto de Roma, concebido como un régimen convencional con potencialidades objetivas, constituye un escenario perfecto para el análisis de este proceso, pues vendría a conformar la tercera fase en la evolución del Derecho internacional de los derechos humanos hacia las nuevas alternativas de justicia que presenta el orden penal internacional. Tanto el Estatuto de la CPI como los Principios y directrices básicos de las Naciones Unidas sobre el derecho de las víctimas hacen alusión a esta doble dimensión al constatar el compromiso de la comunidad internacional respecto del sufrimiento no solo de las víctimas, sino también de los supervivientes y las generaciones futuras, esto es, la humanidad.

Pero no solo es una cuestión de tensión entre lo estatal y lo humano, sino también entre lo colectivo (o comunitario) y lo individual. $\mathrm{Y}$ aquí es donde se sitúa el excelente y oportuno trabajo de la Profesora Orihuela Calatayud que des- de el pormenorizado análisis de la regulación de los derechos de participación de la víctima previstos en el Estatuto de la CPI y su normativa de desarrollo (en particular, las Reglas de Procedimiento y Prueba, RPP) confluye sosegadamente en un anhelado Capítulo V relativo a la valoración del sistema de participación así como a la presentación de propuestas de mejora. En este recorrido, como no podría ser de otro modo, se nos da cuenta de cómo, en el breve periodo de vigencia de actuación de la Corte, se han resuelto las pretensiones alegadas en las solicitudes de participación de las víctimas en atención a la normativa existente y los criterios interpretativos adoptados por la Fiscalía y las distintas Salas jurisdiccionales de la CPI. La autora, consciente del estadio aún incipiente de la novedosa regulación del Estatuto de Roma sobre la condición de las víctimas, ha optado por una exposición más pragmática que crítica situando en el texto de su trabajo el escenario procesal y vital originado por esta reglamentación y práctica judicial.

A lo largo del estudio está sobrevolando el leitmotiv de la justicia encomendada a la Corte respecto de las víctimas. No en vano, la Profesora Orihuela Calatayud introduce, valora y concluye su monografía reflexionando sobre la concepción y naturaleza retributiva (punitiva) o restaurativa del sistema de justicia que ha de impartir la CPI en función de la potencialidad legitimadora prevista en el art. 68.3 del Estatuto, que garantiza en toda fase del juicio la participación de las víctimas en defensa de sus intereses personales afectados de manera que no redunde en detrimento de los derechos del acusado o de un juicio justo e imparcial ni sea incompatible con estos. Como indica la autora, el Estatuto de Roma no se limitó a asumir una función exclusi- 
vamente punitiva de su función jurisdiccional y una concepción utilitarista de las víctimas que reduce el papel de las mismas al de meros testigos (p. 21), sino que «los negociadores del Estatuto quisieron añadir a la Corte una función diferente e íntimamente conectada con el reconocimiento de los derechos de participación y reparación de las víctimas, una función restaurativa, hasta ese momento ajena a los tribunales penales internacionales existentes [...] La valoración del sistema de participación de las víctimas establecido en las normas de la Corte debe efectuarse, por tanto, teniendo en cuenta esta doble finalidad y, en el caso de que la misma denote alguna carencia o inconveniente, ser un acicate para la reflexión y la presentación de propuestas de mejora que resulten viables aunque ello suponga la necesidad de poner en marcha reformas en el sistema normativo de la Corte Penal internacional» (p. 196).

El lector que se acerque a esta obra sobre Las Víctimas y la Corte Penal Internacional va a poder, de nuevo, constatar el buen hacer investigador, científico y literario de la Profesora Orihuela Calatayud. A través de una brillante y contenida prosa, que apuesta por la crónica normativa y jurisprudencial de la materia tratada jalonada de una exhaustiva bibliografía, la monografía se estructura en cinco capítulos, flanqueados por una introducción y los correspondientes apartados de conclusiones, bibliografía y documentación, al que se incorporan unos didácticos anexos sobre los derechos y prerrogativas de las víctimas en las distintas fases del proceso en que participan, el listado de decisiones de la Corte citadas y un esquema sobre las fases del procedimiento.

En los distintos Capítulos se procede al examen de los medios jurídicos y materiales destinados a facilitar la participación de las víctimas ante la Corte. Entre los distintos temas de interés destacan las reflexiones sobre el papel que han de desempeñar la Oficina Pública de
Defensa de las Víctimas y otras dependencias de la Secretaría (resaltándose además que para que las víctimas conozcan plenamente sus derechos y posibilidades de acción, será necesario crear un sistema de proyección exterior con las organizaciones locales y una red de información inclusiva entre la Corte y las comunidades y colectivos afectados); la problemática acerca de las medidas especiales previstas en las Reglas 87 y 88 RPP cuya finalidad es proteger la identidad e integridad de las víctimas, previéndose el controvertido supuesto excepcional y condicionado del anonimato absoluto frente al acusado; y el análisis de la definición de la condición de víctima de acuerdo con las previsiones de la Regla 85 RPP, de los presupuestos necesarios para la presentación de la solicitud de intervención ex Regla 89.1 RPP, así como de las condiciones impuestas a la participación al amparo del art. 68.3 del Estatuto. En torno a estas cuestiones, el Capítulo II incide sobre la posibilidad de la participación de las víctimas indirectas $\mathrm{y}$ de las personas jurídicas o morales perjudicadas; si el daño ocasionado por las víctimas directas a otras personas puede convertir a estas en víctimas indirectas (el caso de los niños soldados); la prueba de la identidad de la víctima y la posibilidad de solicitudes colectivas y simplificadas; el alcance procedimental de la condición de víctimas y, en particular, el tratamiento jurisprudencial otorgado a la afección de los intereses personales de la víctima tanto respecto de las situaciones generales como de los casos concretos planteados ante la Corte.

En el Capítulo III, eje nuclear de la obra, se sistematiza el régimen general de la participación de las víctimas, desde la fase preliminar y de investigación hasta la fase de apelación y solicitud de reparación. En este Capítulo se muestran las tensiones derivadas del no reconocimiento de legitimación activa ni del estatuto de parte a las víctimas y la necesidad de proteger el derecho de defensa de los 
acusados. Tomando como referencia las observaciones presentadas por la Jueza Steiner, se precisan, entre otros, los derechos que integran el estatuto de la víctima y las condiciones requeridas para restringir tales derechos o someter su ejercicio a solicitud y autorización específica por la Sala correspondiente, como es el caso de su participación en los interrogatorios de los testigos o la presentación de pruebas en principio reservada a las partes. El esquema capitular de la obra concluye con la presentación de propuestas de mejora en atención a la valoración de la condición de la víctima reconocido por la Corte, entre las que destacan la posibilidad de presentar solicitudes parcial o totalmente colectivas (sin modificar el carácter individual del daño); la previsión de reforzar el papel de la Secretaría en la tramitación de las solicitudes y la limitación del plazo de presentación; así como la oportunidad de considerar que las decisiones sobre las solicitudes de las víctimas sean adoptadas por las Salas sin que las partes tengan la posibilidad de presentar observaciones (decisiones judiciales no litigadas). Igualmente, y en aras a alcanzar una función restaurativa por parte de la Corte, se propone que esta pueda llegar a asumir capacidades y procedimientos de carácter "transicional», en particular respecto de crímenes perpetrados por niños soldados o en relación con aquellos crímenes cuya persecución la Fiscalía no considere prioritarios en un momento dado. Según la autora, "esta función educativa y preventiva de los procedimientos restaurativos, podría hacer de la Corte un instrumento al servicio de la paz y seguridad internacionales» (p. 220).

A la espera de conocer cuál será la dinámica futura de la CPI, la monografía de la Profesora Orihuela Calatayud constituye una parada obligada para todos aquellos que se interesen por el devenir no solo del estatuto jurídico de las víctimas de los atroces crímenes internacionales, sino del grado de humanización que la comunidad internacional permite que su sistema jurídico asuma en este nuevo milenio.

Francisco JimÉNEZ GARCíA Universidad Rey Juan Carlos http://dx.doi.org/10.17103/redi.68.1.2016.5.03

\section{Pons Rafols, X., Cataluña: Derecho a decidir y Derecho internacional, Madrid, Reus Editorial, 2015, 334 pp.}

Es esta una obra ejemplar. Pero no solo por el rigor de la argumentación, la exhaustividad de las fuentes utilizadas y la solidez del análisis urdido, sino también por la franqueza con la que el autor, catedrático de Derecho internacional público y relaciones internacionales que ejerce este oficio en la Facultad de Dret de la Universitat de Barcelona, enuncia el propósito que persigue.

En un momento en el que España vive uno de los conflictos internos más graves, la amenaza de secesión de Cataluña, un conflicto que alterna el estado larvario con el adulto, y que, quizás no por casualidad, se manifiesta con estrépito en los momentos en que las crisis socia- les y políticas alcanzan en nuestro país el estado agudo - ¿hay que recordar hitos como los de 1917, la Segunda República o la Transición?-, en un momento como ese, Xavier Pons Rafols, por si no hubiera quedado claro con el título del libro, confiesa sus propósitos en la Introducción: «El objeto de este estudio es el de ofrecer una revisión amplia y fundamentada de los principios y normas del Derecho internacional relacionados con el derecho de autodeterminación y, especialmente, procurar un análisis de todas aquellas normas y principios del Derecho internacional que pueden relacionarse con lo que en los últimos años ha venido en denominarse como el derecho a decidir». 
Ni que decir tiene que el juicio de la razón al que somete el Profesor Pons las "pretensiones secesionistas» de fundamentar el «difuso concepto» del «derecho a decidir» «en principios y normas del Derecho internacional o en los pronunciamientos de instituciones internacionales» constituye un discurso polémico. Pons construye y expresa una opinión jurídica, pero sabedor de que toda opinión es (casi) siempre una opinión contra alguien o contra algo, no lo oculta: identifica pronto y con elegancia al adversario intelectual. La obra se dirige contra la tesis que postula que las normas internacionales, o la Opinión consultiva de la Corte Internacional de Justicia en el asunto de Kosovo, amparan directamente un proceso de secesión o separación del Estado como el emprendido por algunos partidos en Cataluña con el apoyo electoral de un sector relevante de la ciudadanía.

A ese campo polémico sale el Profesor Pons - porque no parece que, como decía Cervantes, «ningún peligro (le ponga) miedo» aunque no sabemos si recelo- con las armas de la razón y las letras de su libro a batallar con esas confusas o difusas tesis, a combatir esas ideas, pero siempre con miramiento y consideración a quien las defienda. Porque esa es otra de sus premisas: se critican las ideas pero se respeta al adversario, que expresa una aspiración política legítimamente democrática — «hacer un referéndum o una consulta o, incluso, la misma independencia de Cataluña»-, aunque ha de postularla y ejercitarla — recuerda y sentencia el autor- "sobre la base del principio democrático y en el marco del Estado de Derecho y respetando la legalidad; y España es un Estado democrático y de Derecho».

En esta querella y con este talante o disposición se aventura Pons Rafols en la polémica. Sometiendo, como se hace en toda querella jurídica, pero en este caso no al juez, sino al Tribunal de la razón, argumentos objetivos, pruebas y razona- mientos sólidamente fundados, y luego que el lector juzgue y, si lo tiene a bien, que el político escuche y lo lleve con paciencia. Sabiendo además que la conclusión aprovecha, como se dice en las Partidas, «a todos los hombres de la tierra comunalmente», pues igual que en un juicio con la sentencia «se escarmienta derechamente el malhechor», diríamos que aquí se ajustan las cuentas al contrabandista intelectual.

Con estas armas sale Xavier Pons de la torre de marfil y del ámbito aséptico de la reflexión a querellarse intelectualmente, pero lo hace sine ira et studio, sin abandonar en la andadura la condición y el rigor académicos. En el siglo pasado esta actitud se identificaba con la propia de un "intelectual comprometido»; hoy quizás el Profesor Pons, con la elegancia argumental que practica a lo largo de su estudio, se limitaría a recordar al clásico, con voz queda, sin énfasis ninguno: Soy hombre, nada humano me es ajeno, menos aún si soy ciudadano en Cataluña.

En esta batalla, el autor no está en soledad, aunque tampoco en compañía nutrida. A vuela pluma, cabe recordar ahora, entre los iusinternacionalistas, la aportación breve, clara y precisa, del Profesor Carrillo Salcedo ( «Sobre el pretendido "derecho a decidir" en el Derecho internacional contemporáneo», El Cronista del Estado Social y Democrático de Derecho, núm. 33, enero de 2013), las de la Profesora Mangas Martín («Cataluña: ¿No habrá independencia?», ibid., núm. 42, febrero de 2014, y «La secesión de territorios en un Estado miembro: efectos en el Derecho de la Unión Europea», RDUE, núm. 25, 2013, así como frecuentes colaboraciones en la prensa), o las muy recientes del Profesor Martín y Pérez de Nanclares («Reflexiones jurídicas a propósito de una eventual declaración unilateral de independencia de Cataluña: un escenario político jurídicamente inviable», disponible desde septiembre de 2015 en las páginas web del Ministerio de Asuntos Exteriores y de 
Cooperación y del Real Instituto Elcano, y «Legal considerations regarding a hypothetical unilateral declaration of independence by Catalonia: A legally unfeasible political scenario», SYbIL, núm. 19, 2015). Al debate se sumó también el Profesor Medina Ortega con su monografía El derecho de secesión en la Unión Europea (Madrid, Fundación Alfonso Martín Escudero, Marcial Pons, 2014), en la que, pese a su carácter en apariencia genérico, no se ahorran las referencias al caso catalán, y de la que en 2013 había ofrecido un anticipo en «Los ciudadanos europeos y la secesión de territorios en la Unión Europea» (RDUE, núm. 25). A la formación de este corpus analítico contribuyeron asimismo constitucionalistas, administrativistas y aun consejeros de Estado, algunos con el ánimo de un jurisconsulto que sale al campo, con mano samaritana, a ayudar a encontrar un camino (que no sea el de salida) al caminante. Recordemos aquí hoy a F. Rubio Llorente, y a S. Muñoz Machado, J. Tornos Mas o M. Herrero y Rodríguez de Miñón.

Quizás mucho esfuerzo individual disperso ante una actuación institucional tenaz y planificada del Gobierno de la Generalitat, que alentó, estableció y financió un «Consejo Asesor para la Transición Nacional» para alumbrar, ante la pasividad del Gobierno del Estado, los varios estudios e informes que configuran el denominado Libro Blanco para la Transición Nacional. Precisamente con esos planteamientos doctrinales polemiza el Profesor Pons Rafols caballerosa y denodadamente a lo largo del libro, no sin antes lamentar su soledad y echar en falta una actitud como la del Gobierno del Reino Unido con ocasión del referéndum en Escocia: "Para que los ciudadanos de Cataluña y del resto del Estado pudieran disponer de mayor información y pudieran contrastarla, quizás hubiera sido necesario que el Gobierno español, como se hizo en el Reino Unido de manera previa al referéndum en Escocia, hubiera elaborado Informes, también de impecable factura técnica, sobre las consecuencias de las hipótesis contempladas en el proceso político catalán, [...] solo el Ministerio de Asuntos Exteriores y de Cooperación hizo público y distribuyó entre las embajadas de España un Informe sobre Cataluña y el Derecho internacional, en mayo de 2014». Quien haya leído un escrito tan breve como claro y combativo con los molinos de viento como el de J. Borrell y L. Llorach, Las cuentas y los cuentos de la independencia (Madrid, Catarata, 2015) se preguntará si no podía haber hecho algo igualmente riguroso, con distintos tono y estilo, el Ministerio de Hacienda. ¿Pensaba el Gobierno de la Nación que tenía enfrente solo algarabía digna de silencio solemne y campanudo?

$\mathrm{El}$ «derecho a decidir», invocado profusamente en Cataluña (sin que quepa descartar que, por repetida, esa voz tenga eco en otras partes de España), y el proceso que desencadena, pretenden anclarse en el Derecho internacional. Como señala Xavier Pons Rafols, "se vinculan argumentalmente, de una parte, al derecho de autodeterminación, es decir, al derecho inalienable de todos los pueblos a determinar libremente su futuro y condición política, económica y social; y, de otra parte, a un también inalienable principio de carácter democrático asociado a la expresión de la voluntad popular. Ambos aspectos han experimentado importantes desarrollos en el Derecho internacional contemporáneo por lo que —añade- creo imprescindible explorar su exacto alcance y la medida de su pertinencia en el actual contexto político catalán».

$\mathrm{Y}$ a esto se dedican los seis capítulos del libro. En el primero se estudia cómo eclosiona en la política catalana el famoso «derecho a decidir» (locución importada en territorio español por nacionalistas vascos y traducción, por cierto, del "right to decide», con clara raigambre y amplio desarrollo en el derecho a la inclusión social de las personas con discapacidad, aunque no hay prueba de que 
estemos ante un caso de estraperlo intelectual), se explora la incidencia que tuvo en su germinación la sentencia del Tribunal Constitucional sobre el Estatuto de Autonomía de Cataluña, y se expone el desarrollo del "procés» tras las elecciones autonómicas de noviembre de 2012 y de la «consulta» de noviembre de 2014; por último, se acota el significado y efectos de ese dichoso derecho.

En el capítulo segundo se expone la posición del Tribunal Constitucional ante tal derecho mediante el estudio de sus pronunciamientos sucesivos, ya fueran con ocasión de Declaraciones «de soberanía y del derecho a decidir del pueblo de Cataluña», efectuadas por el Parlament, o de la aprobación de instrumentos que lo facilitan o encauzan, como la Ley de consultas populares no referendarias y otras formas de participación ciudadana.

Fijado este marco, el capítulo tercero analiza y acota el alcance del principio de libre determinación de los pueblos en el Derecho internacional y el de su desarrollo efectivo en el ámbito de las Naciones Unidas, exponiendo el proceso de aparición de los nuevos Estados independientes que propicia y la inefectividad de las pretensiones secesionistas una vez ejercida la libre determinación, para terminar con el análisis de la vinculación entre dicho principio y el democrático, y con el examen de la dimensión interna de la libre determinación de los pueblos y los límites que tiene su ejercicio: la integridad territorial y la cláusula democrática sobre el gobierno representativo.

El capítulo cuarto se centra en el estudio del régimen en el Derecho internacional de la separación de una parte del territorio de un Estado. Para ello, en él se estudia el desarrollo y evolución de los procesos de separación y disolución de Estados en la Europa central y oriental, la integridad territorial de esos nuevos Estados y los límites a las secesiones recursivas; se analiza también cómo se abordaron en algunos Estados democráticos las tensiones secesionistas, en concreto cómo se encauzó en Canadá la demanda secesionista de Quebec y en el Reino Unido la de Escocia. Termina este capítulo con el estudio del supuesto de Kosovo y del alcance de la Opinión Consultiva de la CIJ; en definitiva, con el análisis de la compatibilidad con el Derecho internacional de una declaración unilateral de independencia, la vía por la que parecen haber optado decididamente algunas organizaciones políticas en Cataluña.

El capítulo quinto examina la formulación y desarrollo de los derechos humanos, la democracia y el Estado de derecho en el Derecho internacional y en el Derecho español, y cómo interaccionan esos tres factores, dedicando una especial atención a las obligaciones en materia de derechos humanos, democracia y Estado de Derecho en el ámbito europeo, específicamente en el Consejo de Europa y en la Unión Europea.

En el capítulo sexto se aplican los anteriores desarrollos al caso catalán, es decir, se efectúa un pronunciamiento sobre el «derecho a decidir» la independencia de Cataluña y su legitimación internacional. Para ello se estudia el alcance de los criterios internacionales sobre procesos electorales y referendarios, las garantías democráticas reconocidas internacionalmente y se contrastan con las actuaciones de ejercicio del derecho a decidir en Cataluña. Finalmente, se enjuician las pretensiones secesionistas en ese territorio a la luz del Derecho y la práctica internacionales, y tras exponer los argumentos de base que pretenden sustentar un amparo internacional al derecho a decidir la independencia, se concluye en la inconsistencia con la legalidad internacional de una secesión de carácter unilateral en un contexto democrático, exponiendo igualmente los efectos del reconocimiento internacional de Estados y del principio de la no intervención en los asuntos internos de otros países. 
La conclusión acerca de la ilegalidad de algunas de las vías que se postulan para encauzar las pretensiones secesionistas en Cataluña no lleva al autor del libro, sin embargo, a erigirla en un «muro infranqueable $\mathrm{u}$ obstáculo al desarrollo y al ejercicio de la voluntad democrática de una sociedad», de modo que «un Estado democrático no puede permanecer silente frente a la voluntad claramente expresada por una amplia mayoría de la población - ya sea del conjunto del Estado o de un territorio concreto- a través de procesos democráticos, como unas elecciones o un referéndum o consulta: debe darle una respuesta y una solución política». Pero el marco en que se desarrolle y el modo de encauzarla es uno y solo uno: «Desde la perspectiva de la legalidad internacional [...] la respuesta a los importantes cambios políticos, económicos y sociales que estamos presenciando a escala internacional, así como la respuesta a las elevadas expectativas políticas respecto del denominado derecho a decidir y del proceso soberanista que se han generado en Cataluña - tan legítimas y posibles como cualesquiera otras opciones políticas y democráticas-, deben basarse en el Estado de Derecho y en el imperio de la ley, la base sobre la que se construyen sociedades justas y equitativas».

Tras culminar esta obra, tras culminar esta aventura, mediado abril de 2015, cuando firma la Introducción, el Profesor Pons podría haberse retirado a descan- sar un tiempo. Pero en ese tiempo, como prueba de que convencer es cosa distinta de convencerse, celebráronse en Cataluña elecciones autonómico-plebiscitarias, $\mathrm{y}$ vencieron-perdieron en ellas unas fuerzas políticas que entretanto proclamaron solemnemente en el Parlamento de Cataluña «el inicio del proceso de creación del Estado catalán independiente en forma de república; [...] el comienzo de un proceso constituyente ciudadano, participativo, abierto, integrador y activo para preparar las bases de la futura Constitución catalana», y reiteraron «que este Parlamento y el proceso de desconexión democrática no se supeditarán a las decisiones de las instituciones del Estado español, en particular del Tribunal Constitucional, al que considera deslegitimado y sin competencia desde la Sentencia de junio de 2010 sobre el Estatuto de Autonomía de Cataluña votado previamente por el pueblo en referéndum, entre otros».

Y en esas estamos. Como dijo el jurista Joseph Reinach con ocasión de un sonado "affaire»: "Ce ne sont plus les faits contrôlés, les choses examinées avec soin qui forment la conviction; c'est la conviction souveraine, irrésistible, qui déforme les faits et les choses». Vale.

Paz Andrés Sáenz de Santa María Catedrática de Derecho internacional público

Universidad de Oviedo http://dx.doi.org/10.17103/redi.68.1.2016.5.04

YTURRIAGA BARBERÁN, J. A., Los órganos del Estado para las relaciones exteriores. Compendio de Derecho Diplomático y Consular, Madrid, Ministerio de Asuntos Exteriores y Cooperación, Colección Escuela Diplomática, 2015, 549 pp.

La última publicación del Embajador Yturriaga, cuyo origen se encuentra estrechamente relacionado con la participación del autor como profesor en el Máster propio en Derecho internacional y Relaciones internacionales de la Universidad Complutense de Madrid, se distingue de otras obras sobre la misma temática que la han precedido en la doctrina española y extranjera por su carácter exhaustivo, pues, junto a los capítulos relativos al estudio de las misiones diplomáticas y consulares, incluye también otros dedicados al análisis de las funcio- 
nes y el estatuto jurídico internacional de los órganos centrales del Estado para las relaciones exteriores, de las representaciones permanentes de los Estados ante las Organizaciones internacionales, de las misiones especiales y de la diplomacia de conferencia.

Con un enfoque esencialmente didáctico, orientado a servir de apoyo a la actividad docente y discente en cursos de cualquier nivel académico sobre Derecho internacional público o sobre Derecho diplomático y consular, esta monografía se beneficia de la dilatada experiencia del autor en el ejercicio de numerosos, variados e importantes puestos en el Servicio Exterior español, habiéndose desempeñado como embajador ante distintos Estados, como representante permanente ante Organizaciones internacionales, como delegado en Conferencias internacionales, como embajador en Misión Especial y como cónsul, lo que le permite redactar muchos de los párrafos en primera persona, constituyendo sus vivencias uno de los aspectos más interesantes y una de las aportaciones más relevantes del estudio, pues, al ir más allá de la mera descripción de las normas internas e internacionales aplicables a cada cuestión examinada, permite conocer la realidad de las relaciones exteriores no solo en el aspecto meramente teórico de su regulación formal, sino también desde el punto de vista de la realidad práctica, lo que, además de enriquecedor, resulta ameno $\mathrm{y}$ en ocasiones hasta divertido, gracias a las muchas anécdotas que oportunamente se van intercalando en el texto, si bien en otros casos las enseñanzas derivadas de la experiencia han resultado bastante amargas, destacando en este apartado los lamentables sucesos vividos con ocasión del asalto a la Embajada de España en Portugal en 1975.

Además de ese significativo bagaje, otros hitos no menos importantes en la carrera profesional del Embajador Yturriaga que han dejado también poso en esta obra son su puesto al frente de la
Asesoría Jurídica Internacional del Ministerio de Asuntos Exteriores y, en el ámbito académico, su actividad docente como profesor en las Facultades de Derecho y Ciencias Políticas de la Universidad Complutense de Madrid — con la que sigue colaborando en la actualidad-, en la Escuela Diplomática y en la Academia de Derecho Internacional de La Haya, que le permite tener siempre presente el fin último de la misma como herramienta de trabajo para profesores y alumnos y le lleva a adoptar un estilo muy pedagógico y de fácil comprensión, que huye del tratamiento docto y erudito de los problemas sin renunciar por ello a la profundidad y el rigor en el análisis.

Por otra parte, al margen de la elevada calidad del resultado final, que es sin duda el aspecto más relevante de esta monografía, llama la atención tanto el intenso ritmo de trabajo del autor, como la gran productividad obtenida de la dedicación y el esfuerzo intelectual aplicados en su elaboración, cuestiones que no necesariamente van unidas. Prueba de ello es que el Embajador Yturriaga se propuso preparar el presente Compendio cuando terminaba el curso académico 2014-2015 y ha logrado concluirlo antes de que finalizara ese último año natural, a pesar de la ingente cantidad de referencias bibliográficas y jurisprudenciales, así como de materiales de la práctica internacional, que ha manejado para su redacción. Ello no impide, sin embargo, que cada capítulo se perciba por el lector como fruto de una sosegada reflexión.

En cuanto al contenido de la obra, tras un primer capítulo de carácter introductorio, en el que se expone el concepto y la evolución histórica de la diplomacia, su relación con la política exterior, los efectos que sobre la misma han tenido la globalización y la creciente importancia otorgada por la comunidad internacional al respeto de los derechos humanos y de los principios democráticos, así como los presupuestos necesarios para el establecimiento de las relaciones internaciona- 
les; los siguientes capítulos reproducen una misma estructura, que resulta clara y esclarecedora, por bien organizada. Así, el segundo de ellos se dedica al estudio de los jefes de Estado y/o de Gobierno y los ministros de Asuntos Exteriores, centrándose en la evolución del papel que desempeñan tan altas autoridades en las relaciones internacionales del Estado al que representan, así como en el análisis de las funciones que les corresponden en dicho ámbito y del alcance y contenido de los privilegios e inmunidades que les reconoce el Derecho internacional.

A continuación, en el capítulo tercero, sobre las misiones diplomáticas — que es el más extenso de la obra, junto con el siguiente, dedicado a las misiones consulares, como resulta comprensible, pues se trata de los sectores donde rige una regulación jurídica más antigua, detallada y ampliamente aceptada por los Estados y en los que la práctica resulta más abundante-, el autor describe el origen y la evolución histórica de las mismas; expone y comenta las reglas que rigen su establecimiento y el nombramiento y la acreditación de su jefe, así como la terminación de aquella y el cese de las funciones de sus miembros; analiza sus funciones; describe su estructura; enumera sus medios de acción, aportando información para identificarlos y distinguirlos entre sí, muy útil para los profanos; y estudia sus inmunidades y privilegios y los del personal que las integran, con especial referencia a algunos supuestos de la práctica bien conocidos en los que fueron gravemente violados.

Siguiendo un esquema similar, el cuarto capítulo repasa las profundas transformaciones que ha experimentado la institución consular a lo largo de su evolución histórica; el concepto de cónsul; el procedimiento y los requisitos para el inicio de las misiones consulares, con especial referencia a la figura del exequátur, y las causas y consecuencias de su terminación; las funciones de naturaleza política, administrativa, jurídica y asis- tencial que desempeñan —centrándose en las principales, pues, en la práctica, la relación completa de las mismas supera las enumeradas por la Convención de Viena de 1963, tal y como la misma prevé- y cómo estas han ido variando para adaptarse a las necesidades de cada momento; sus clases, su estructura y organización y sus medios de acción; así como los privilegios e inmunidades que disfrutan tanto la propia oficina consular como el personal consular que desempeña sus funciones en ella.

Por su parte, el capítulo quinto se dedica al estudio de las representaciones permanentes de los Estados ante las Organizaciones internacionales, cuya regulación trasciende la bilateralidad, en la medida en que las funciones de estas representaciones se ejercen y los privilegios e inmunidades se disfrutan en el territorio del Estado sede de la organización, lo que da lugar a una especie de relación triangular. A ello se une el hecho de que estas representaciones no se rigen por ninguna Convención internacional de carácter general, pues la adoptada con tal fin en Viena en 1975 no ha entrado en vigor, de modo que los aspectos fundamentales de su funcionamiento se regulan por las normas establecidas al respecto en los tratados constitutivos de cada Organización internacional, en los convenios sobre privilegios e inmunidades de las mismas y en los acuerdos de sede, si las hubiere, así como por las reglas relativas a las misiones diplomáticas, añade el Embajador Yturriaga, que resulten aplicables en virtud del Derecho consuetudinario. En tal normativa, variada y particularista y en la práctica sobre la materia se basa el análisis del fin de la representación permanente, sus funciones, su estructura y medios de actuación y sus privilegios e inmunidades.

Para terminar, el autor dedica los dos últimos capítulos de la obra al examen de la denominada diplomacia ad hoc, y en especial a las misiones especiales y a la diplomacia de conferencia, a las que 
se refieren los capítulos sexto y séptimo, respectivamente. En ambos casos se analizan, siguiendo la estructura conocida, que otorga homogeneidad a la obra en su conjunto, las reglas sobre el principio y fin de dichas representaciones, su estructura y los medios de acción con los que cuentan, sus funciones y sus privilegios e inmunidades, codificadas, por lo que se refiere a las primeras, en la Convención sobre la materia adoptada por la Asamblea General de las Naciones Unidas de 1969 y, en cuanto a la segunda, en la Convención de Viena de 1975 sobre representación de los Estados ante las Organizaciones internacionales universales, cuando se trate de Conferencias convocadas por dichas organizaciones o bajo sus auspicios.

Cierra la obra una extensa y útil bibliografía, organizada por temas, junto con un índice de materias y otro onomástico.
A modo de valoración final, este Compendio constituye un estudio extenso y en profundidad, concebido para destacar su aspecto didáctico, que va mucho más allá de la mera transcripción de las normas jurídicas aplicables a cada cuestión examinada, pues aporta elementos que sirven para contextualizarlas e indaga en su razón de ser, además de que ilustra acerca del modo en que son aplicadas en la práctica, acercando la diplomacia, entendida en sentido amplio, a cualquier lector interesado en las relaciones internacionales y, especialmente, a los profesores y alumnos que se dedican a su enseñanza y estudio, tanto en el marco de titulaciones oficiales, como en el de los cursos no reglados organizados al margen de las mismas.

Rubén CARNERERo CASTILla Universidad Complutense de Madrid http://dx.doi.org/10.17103/redi.68.1.2016.5.05 